\title{
Recurrent non-epileptiform seizure-like phenomena secondary to propofol administration
}

\author{
Shannon M. Fernando, MD, MSc $\cdot$ Tess Fitzpatrick, MD $\cdot$ Heather Hurdle, MD, MSc • \\ Arun Anand, MD · Christopher R. Skinner, MD • Kirsty U. Boyd, MD • \\ George Dumitrascu, MD $\cdot$ Jonathan Hooper, MD
}

Received: 6 September 2016/Revised: 1 March 2017/ Accepted: 17 March 2017/Published online: 27 March 2017

(c) Canadian Anesthesiologists' Society 2017

\section{To the Editor,}

Propofol is a short-acting, lipophilic anesthetic and has been used to treat refractory status epilepticus. ${ }^{1}$ However, there have been reports of propofol-induced "seizure-like phenomena" (SLP). ${ }^{1}$ Little is known regarding the underlying pathophysiology or electroencephalographic correlates of SLP, ${ }^{1,2}$ and no reports of recurrent SLP exist.

We report a case of a 57-yr-old male, admitted for ulnar nerve transposition. Past medical history included mitral valve prolapse, gastro-esophageal reflux, dyslipidemia, and no known drug allergies. There was no history of seizures or alcohol/illicit drug abuse. Prior anesthetic history was unremarkable. Induction of anesthesia was achieved with

Electronic supplementary material The online version of this article (doi:10.1007/s12630-017-0869-1) contains supplementary material, which is available to authorized users.

S. M. Fernando, MD, MSc ( $\varangle)$

Department of Emergency Medicine, University of Ottawa,

Ottawa, ON, Canada

e-mail: sfernando@toh.ca

S. M. Fernando, MD, MSc $\cdot$ J. Hooper, MD

Division of Critical Care, Department of Medicine, University of

Ottawa, Ottawa, ON, Canada

T. Fitzpatrick, MD · C. R. Skinner, MD

Division of Neurology, Department of Medicine, University of Ottawa, Ottawa, ON, Canada

H. Hurdle, MD, MSc · A. Anand, MD .

G. Dumitrascu, MD · J. Hooper, MD

Department of Anesthesiology, University of Ottawa, Ottawa,

ON, Canada

K. U. Boyd, MD

Division of Plastic Surgery, Department of Surgery, University of Ottawa, Ottawa, ON, Canada midazolam (2 mg), fentanyl (200 $\mu \mathrm{g})$, propofol (200 mg), and dexmedetomidine $(44 \mu \mathrm{g})$. General anesthesia was maintained using sevoflurane and a dexmedetomidine infusion. Reversal of anesthesia, including awakening and extubation, were unremarkable. Total surgical time was $90 \mathrm{~min}$. The patient was monitored in the postanesthesia care unit for ongoing nausea. Four hours postoperatively, the patient was witnessed to have a 15-min episode of what appeared to be uncontrollable shivering. Bilateral arm and leg movements were observed, with associated tachycardia (heart rate 204 beats. $\mathrm{min}^{-1}$, tachypnea (respiratory rate 24 beats $\cdot \mathrm{min}^{-1}$ ) and subsequent desaturation $\left(\mathrm{SpO}_{2}\right.$ 85\%). He was able to speak throughout. Oxygen saturation improved to $95 \%$ with supplemental oxygen, and temperature was $36.5^{\circ} \mathrm{C}$ at the time of the incident. The etiology of this unusual motor activity was not clearly established.

Eight months later, he returned for revision decompression. Induction of anesthesia was achieved with midazolam (3 mg), fentanyl $(150 \mu \mathrm{g})$, propofol (150 $\mathrm{mg})$, remifentanil $(150 \mu \mathrm{g})$, and succinylcholine $(60 \mathrm{mg})$. Anesthesia was maintained using desflurane (1.0 MAC) and hydromorphone boluses (1.6 mg total). Total surgical time was $100 \mathrm{~min}$. Emergence was initially uneventful, with the patient extubated awake and following commands. Two minutes following extubation, he no longer followed commands. Subsequently, generalized movements of all four extremities appeared (SLP, video: available as Electronic Supplementary Material), and he was treated with intravenous midazolam $(2 \mathrm{mg}$, followed by an additional $1 \mathrm{mg}$ ). The movements stopped after approximately one minute. Despite subsequent treatment with propofol and additional midazolam, intermittent episodes of movements with similar duration followed with increasing frequency throughout the patient's stay in 
the recovery room. He was eventually reintubated and admitted to the intensive care unit. Propofol infusion was initiated at $2.5 \mathrm{mg} \cdot \mathrm{kg}^{-\mathrm{hr}^{-1}}$ and abnormal movements ceased. Neurology was consulted. Non-contrast computed tomography and magnetic resonance imaging of the brain were unremarkable. When the propofol infusion was decreased to $1 \mathrm{mg} \cdot \mathrm{kg}^{-1} \cdot \mathrm{hr}^{-1}$, SLP recurred. Concurrent electroencephalography demonstrated slow background activity, in addition to widespread frequency dispersion in wakeful rhythm (Figure), but no epileptiform activity. Seizure-like phenomena ceased with administration of a 20 $\mu \mathrm{g}$ bolus of dexmedetomidine, followed by a 0.8 $\mu \mathrm{g} \cdot \mathrm{kg}^{-1} \cdot \mathrm{hr}^{-1}$ infusion. He was successfully extubated, and discharged $24 \mathrm{hr}$ later.

The unusual motor responses associated with propofol administration may be secondary to antagonism of glycine receptors located in subcortical structures. ${ }^{3}$ Such antagonism may be more predominant at lower propofol doses, such as during emergence. ${ }^{4}$ Higher doses result in suppression of movements. In our case, SLP appeared to cease during administration of higher propofol doses but re-emerged with decreasing doses. Other theories suggest that abnormal movements are secondary to the effect of toxic metabolites from altered propofol metabolism, or SLP may represent an allergic reaction to preservatives. ${ }^{1} \mathrm{~A}$ psychogenic etiology has also been proposed. ${ }^{1,2}$

Given this behaviour following emergence from the second anesthetic, we re-evaluated the patient's unusual motor responses that followed the first surgical procedure, which led us to postulate that the SLP at that time may also have been associated with propofol administration. An important matter to consider is that the onset of symptoms occurred hours after propofol administration. A $200 \mathrm{mg}$ propofol bolus would yield an expected effective site concentration of $0.06 \mathrm{mg} \cdot \mathrm{L}^{-1}$ at $90 \mathrm{~min}$, and $0.01 \mathrm{mg} \cdot \mathrm{L}^{-1}$ at six hours. ${ }^{5}$ Although these concentrations are subanesthetic, the relationship between the effect site concentration of propofol and SLP has not been elucidated. Propofol is lipophilic, with a large volume of distribution. Thus, despite its initial half-life of

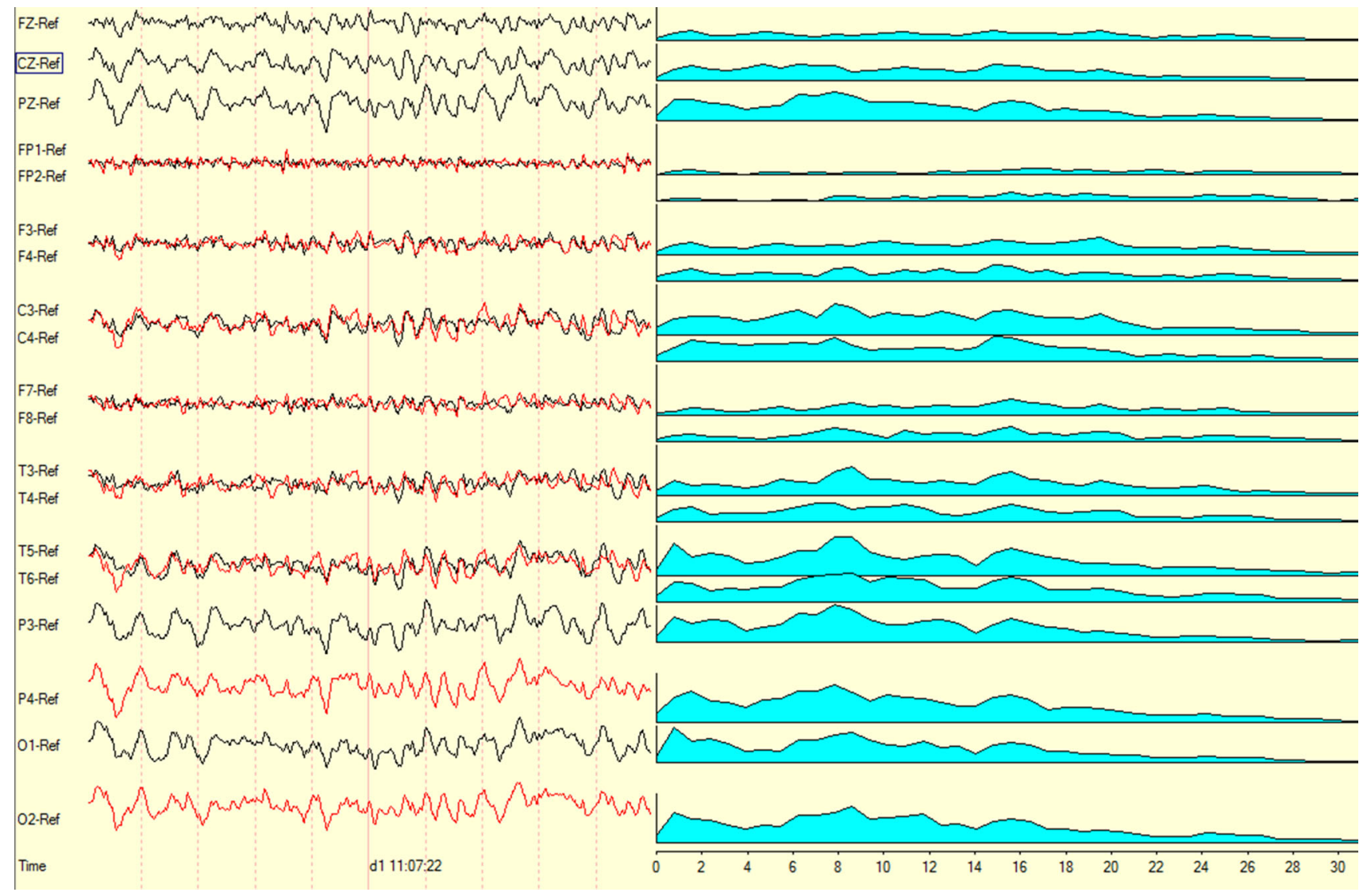

Figure Non-epileptic abnormalities noted on electroencephalogram (EEG) recorded from surface scalp electrodes during seizure-like phenomena that may be propofol related. Left panel: black trace: left hemisphere; red trace: right hemisphere. Right panel: wide-spread frequency dispersions (depicted by frequency distributions in a pattern of multiple peaks) of the corresponding EEG signal shown on right. Sensitivity $5 \mathrm{mcV} / \mathrm{mm}$. Time scale in seconds 
approximately $40 \mathrm{~min}$, it has a terminal half-life that ranges from $60 \mathrm{~min}$ to as much as three days, thereby persisting in the body for hours. ${ }^{1,2}$ About $25 \%$ of cases of SLP attributed to propofol administration occur following emergence. ${ }^{1}$ Of course, we cannot rule out other anesthetic drugs' contribution to the appearance of the observed episodes of SLP. With our patient, the abnormal movements appeared to cease following administration of dexmedetomidine, suggesting that it may be an effective treatment for propofol-induced SLP, possibly by increasing central GABAergic transmission. ${ }^{6}$

Conflicts of interest None declared.

Editorial responsibility This submission was handled by Dr. Steven Backman, Associate Editor, Canadian Journal of Anesthesia.

\section{References}

1. Walder B, Tramer MR, Seeck M. Seizure-like phenomena and propofol: a systematic review. Neurology 2002; 58: 1327-32.

2. Hickey KS, Martin DF, Chuidian FX. Propofol-induced seizurelike phenomena. J Emerg Med 2005; 29: 447-9.

3. Dolin SJ, Smith MB, Soar J, Morris PJ. Does glycine antagonism underlie the excitatory effects of methohexitone and propofol? Br J Anaesth 1992; 68: 523-6.

4. Borgeat A, Dessibourg C, Popovic V, Meier D, Blanchard M, Schwander D. Propofol and spontaneous movements: an EEG study. Anesthesiology 1991; 74: 24-7.

5. Schnider TW, Minto CF, Shafer SL, et al. The influence of age on propofol pharmacodynamics. Anesthesiology 1999; 90: 1502-16.

6. Nelson LE, Lu J, Guo T, Saper CB, Franks NP, Maze M. The alpha2-adrenoceptor agonist dexmedetomidine converges on an endogenous sleep-promoting pathway to exert its sedative effects. Anesthesiology 2003; 98: 428-36. 